\title{
Can the Earth Support Us All?
}

\section{The International Biological Programme Explained}

$$
\text { By E. B. Worthington }
$$

The human race is setting itself some formidable problems by both increasing at an unprecedented rate and raising its living standards at an even faster rate. Have we the resources to feed, house, clothe, let alone provide leisure and culture, for all? What, for example, are the untapped food resources of the sea, of rivers and lakes, of wildlife? Nobody knows. The task of the International Biological Programme is to find the answers. Dr. Worthington, deputy director of the Nature Conservancy, and scientific director designate of the IBP, explains the task, and outlines the methods.

THE demands on biological production throughout the world are increasing at a rate which is positively alarming when you think that the human population is expanding at an accelerating rate and the needs per head are increasing even more rapidly in order to support a rising standard of living. Hence the importance for us to estimate now how far biological production can be induced to meet all forms of human need, not only food and clothing, but also recreation and industry, culture and aesthetics. We have quite good estimates for the "tame" productive capacity of land which is already under the plough or intensive animal farming, but we can still make only vague "guestimates" at the "wild" production that is possible from land that is not intensively managed, as well as from most fresh waters, and all the seas. We need a much better understanding of the productive capacity and processes of plants and animals before we can convert such "guestimates" into reliable figures, and convert "wild" production (most of which is as yet unused by man) into "tame" production. For such understanding international cooperation is essential.

International collaboration in studying the physical environment has already risen to high peaks of achievement in research on the ionosphere, atmosphere, and geosphere, stimulated by organised programmes such as the International Polar Years, the International Geophysical Year, and the International Years of the Quiet Sun. It is going forward strongly, too, with the hydrosphere, as arranged by the International Oceanographic Commission and the International Hydrological Decade, which started in January, 1965. But the biosphere has so far been left rather severely alone.

I am not suggesting that opportunities for the exchange of knowledge and ideas about the biological sciences are lacking. Indeed, they are almost overburdening, for there are international unions and associations in almost every branch of biology ; from spring to autumn scarcely a week passes without some international biological congress, often several running contemporaneously, even in the same country. It is probably the 
very diversity of biological science, the numerous techniques involved, and the fact that in many of them the methodology has not yet crystallised, which makes the organisation of an International Biological Programme so difficult. Geophysicists and hydrologists tend to speak the same language throughout the world, much of it figures and equations ; not so biologists.

During the past year or so the IBP has been taking shape, and it has been found necessary to divide it into no fewer than seven largely distinct, though in some cases overlapping, sections, each of which to be effective will need a world organisation. The common thread which binds them together is " the biological basis of productivity and human welfare", and the objectives are to ensure the world-wide study of two aspects: organic production on the land, in fresh waters, and in the seas, and the potentialities and uses of new as well as existing natural resources; and human adaptability to changing conditions. Discussions as to the form and content of an IBP started in 1959, and a good summary of these by one of the originators, Professor G. Montalenti of Rome, will be found in IBP News No. 1 November, 1964, and another by Professor C. H. Waddington in the New Scientist, May 2nd, 1963. The seven sections into which the programme is divided are:-
PT : Productivity of Terrestrial Communities
PP : Production Processes
CT : Conservation of Terrestrial Communities
PF : Productivity of Freshwater Communities
PM : Productivity of Marine Communities
HA : Human Adaptability
UM : Use and Management of Biological Resources.

Each of these has a Sectional Committee limited to ten members, together with a few corresponding members, selected from prominent biologists in that subject from all over the world. Each Sectional Committee operates under a convener, and it is hoped that each will in due course have a whole-time scientific co-ordinator and suitable professional assistants.

The convener of PT is Professor F. Bourlière, of Paris, who is also President of IUCN; the convener of CT is Mr. E. M. Nicholson, Director-General of the Nature Conservancy. PT has the huge task of trying to co-ordinate and to stimulate studies of both primary (vegetable) and secondary (animal) productivity in all biogeographic regions of the world, and to start this off, during 1965 and 1966 it is organising symposia of selected specialists to define and advise methods that have already proved effective. Among the symposia for 1965 there will be one in Copenhagen in July on the ecology and physiology of plant productivity (in cooperation with Section UM), and another in Aberdeen in September on the ecology and physiology of large herbivores, both wild and tame. Symposia like these, together with the initiation of pilot projects and what are now generally referred to as design and feasibility studies, comprise the first two years' operations for all sections of the programme. This is Phase 1 of the IBP. Phase 2 will comprise about five years' operation of the full programme, after which some of its work will doubtless have to continue under other appropriate auspices. 
The work of CT, Conservation of Terrestrial Communities, will be initially to collect and organise new knowledge about the wild and semiwild ecosystems throughout the climatic and bio-geographical zones of the world. At a later stage it will try to determine which specific areas should be positively conserved and managed, so as to provide as complete a series as possible for permanent study and reference. Since it seems impossible to reach international agreement on any one method of classifying ecosystems, the world survey now being initiated by $C T$ is to be based on objective criteria which can, if necessary, be assessed by nonspecialists and recorded on punch cards. Subsequently the cards can be sorted according to each favoured system of classification. Something comparable will be done for the fresh water of the world by the section PF, Productivity of Freshwater Communities, and a list of key lakes, rivers, and other bodies is already well advanced, having been initiated by the International Limnological Congress some years ago. Section PF's main concern, however, will be with fundamental studies of biological productivity in water, and it has a programme in mind for the great man-made lakes of the tropics, including Volta, Kariba, Kainji and Aswan in Africa, and Brokopondo in South America.

The results which are likely to come out of IBP will of course depend entirely on the effort put into it, and, although a certain amount of assistance is expected from such international organisations as UNESCO, WHO, and FAO, most of the work will need to be done and financed on a national basis. In this Great Britain is already taking a lead. We have a national IBP Committee, organised by the Royal Society, with subcommittees corresponding to the seven sections of IBP. The Research Councils as well as the Royal Society are expected to contribute from their resources; the Nature Conservancy for example, has extended its programme on the productivity of moorlands and woodlands in Britain to be part of the British contribution to IBP. National IBP programmes, however, are not necessarily limited to their country of origin ; they may also embrace research assistance to developing countries. Thus the U.K. programme also includes the establishment of two bases for tropical IBP studies, one in a savanna zone and another in tropical rain forest. Expeditions to little-known areas without local research facilities will also be arranged.

The physical organisation of IBP is very simple. Under the International Council for Scientific Unions (ICSU) there is a Special Committee for IBP (SCIBP), with Professor Jean Baer of Switzerland as President and a membership representative of biological disciplines, co-operating organisations and regions of the world. This has a central executive office temporarily in Rome, but to be moved to London before long into accommodation promised by the Government for use by the Royal Society. A Finance Committee and a Bureau of SCIBP are also serviced by the Central Office. This modest organisation may have to grow as the programme unfolds, particularly by the provision of staff for each of the Sections, but every effort will be made to keep it small. The purpose is to put the maximum effort into field and laboratory work, but with a background pattern related to human needs. 